\title{
Molecular Mechanism of Dioxin Formation from Chlorophenol based on Electron Paramagnetic Resonance Spectroscopy
}

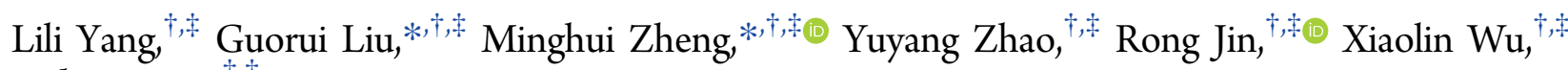
and Yang $\mathrm{Xu}^{\dagger, \dagger}$

\footnotetext{
${ }^{\dagger}$ State Key Laboratory of Environmental Chemistry and Ecotoxicology, Research Center for Eco-Environmental Sciences, Chinese Academy of Sciences, P.O. Box 2871, Beijing 100085, China

*University of Chinese Academy of Sciences, Beijing 100049, China
}

\section{Supporting Information}

ABSTRACT: Few studies have investigated the free radical intermediates involved in the formation of polychlorinated dibenzo- $p$-dioxins and dibenzofurans (PCDD/Fs) from chlorophenol. This study clarified the reaction pathways during thermochemical formation of PCDDs from 2,3,6-trichlorophenol (TCP) over a $\mathrm{Cu}$ (II)O/silica matrix, which was used to simulate fly ash, at $298-523 \mathrm{~K}$. The reaction was studied using electron paramagnetic resonance (EPR) spectroscopy and theoretical calculations. In situ EPR indicated the TCP radical (TCPR) formed by hydrogen abstraction of TCP. Five elementary processes including dimerization of TCPR, orthochloride abstraction, Smiles rearrangement, ring closure, and

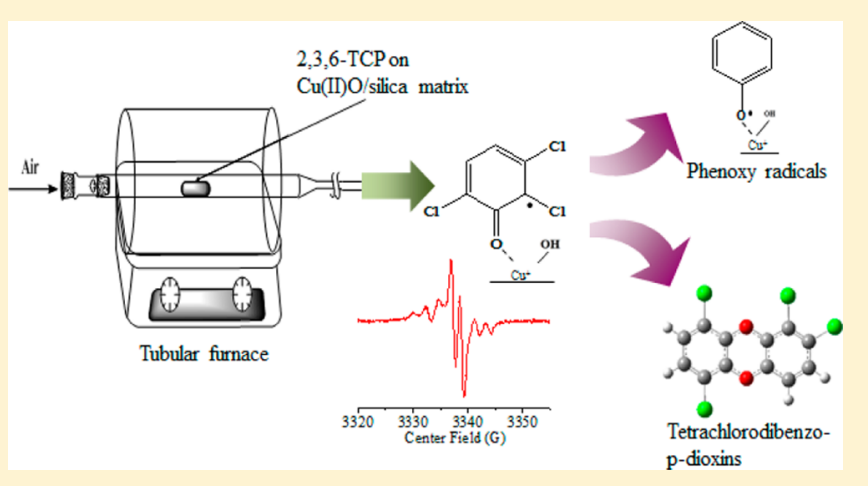
intra-annular elimination of $\mathrm{Cl}$ were proposed to occur during formation of PCDDs. The proposed mechanism was further confirmed by the detection of PCDD products from thermochemical experiments in a tube furnace. Several dominant congeners, including 1,2,6,9-tetrachlorodibenzo- $p$-dioxin (TeCDD), 1,2,6,7-TeCDD, 1,2,8,9-TeCDD, and 1,4,6,9-TeCDD were detected by gas chromatography/quadrupole time-of-flight mass spectrometry, and further confirmed by gas chromatography/high resolution mass spectrometry. The detected PCDD products agree with the proposed PCDD formation mechanism. Relatively high temperatures were found to lead to dechlorination of TCPR to form phenoxy radicals in addition to PCDD/Fs. These radicals will be attached to particles, which will increase their lifetimes. These reactions were further verified by molecular orbital theory calculations. The discovery of persistent phenoxy radicals is of environmental significance because of their potential toxicity. The details of this mechanism could be used for controlling $\mathrm{PCDD} / \mathrm{F}$ formation during industrial thermal processes.

\section{INTRODUCTION}

Polychlorinated dibenzo- $p$-dioxins and dibenzofurans (PCDD/Fs) have high toxicity and bioaccumulate and can be unintentionally produced during multiple industrial thermal processes. ${ }^{1}$ Currently, even though opinions diverge over the formation mechanism of $\mathrm{PCDD} / \mathrm{Fs}$ during thermal and catalytic processes, two categories of formation pathways are widely recognized. The first category includes homogeneous reactions involving chlorinated organic precursors, such as chlorophenols and chlorobenzenes. The second category includes heterogeneous reactions involving de novo synthesis from carbon, chlorine, and oxygen, and chlorinated organic precursors, which occur under the catalysis of metallic oxides in fly ash. Currently, PCDD/F formation pathways are mostly speculative and are from studies of homologue and congener patterns of PCDD/Fs in stack gas or fly ash collected from full-scale facilities. ${ }^{2,3}$ However, the mechanistic details on the molecular level for PCDD/F formation during thermochemical reactions, and especially the intermediates involved in the reactions, have not been clarified to provide sufficient experimental evidence for these reaction pathways.
Chlorophenols are widely recognized to be important precursors for PCDD/Fs. Chlorophenol levels are significantly correlated with unintentional production of PCDD/Fs from industrial thermal sources, and they can even be used as an indicator for fast prediction of the potential PCDD/F emission levels in stack gas. ${ }^{4,5}$ Many laboratory-scale studies have indicated that chlorophenols play a key role in PCDD/F formation, and they are widely recognized as the predominant precursor under pyrolytic or oxidative conditions. ${ }^{6}$ Chlorophenols are structurally similar to PCDD/Fs and abundant in the stack gas from some thermal related industries. ${ }^{6,7}$ For instance, PCDD/ Fs can be formed in the oxidation of chlorinated phenols and chlorinated benzenes under the catalysis of metal oxide particles or catalysts like manganese peroxidase. ${ }^{6,8-10}$ In a previous study, monochlorophenol and dichlorophenol have been used

Received: February 14, 2017

Revised: $\quad$ March 23, 2017

Accepted: March 30, 2017

Published: March 30, 2017 
to investigate the formation of PCDD/Fs. ${ }^{11,12}$ Trichlorophenols that easily produce toxic tetra-chlorinated dioxin isomers during thermal reactions were scarcely studied. In addition, based on molecular orbital theory calculations, trichlorophenol (TCP) such as 2,3,6-TCP are believed to be important precursors for $\mathrm{PCDD} / \mathrm{F}$ formation because they have a high number of chlorine substitutes and relatively lower steric hindrance because of oxygen-carbon coupling. . $^{3,14}$

PCDD/Fs can be formed in the cooling zone of industrial thermal processes, which also generate large quantities of fly ash containing chlorinated organic compounds and particlesupported metallic oxides. ${ }^{15}$ Under the catalytic effect of fly ash containing metal compounds, $\mathrm{PCDD} / \mathrm{Fs}$ can be easily produced during industrial thermal processes. ${ }^{16}$ However, the complexity of the fly ash matrix poses challenges for the detection of free radicals on the molecular scale. Consequently, a bottom-up approach is used, in which the fly ash is separated into its organic, metal oxide, and particulate components, and the role of each of these components is assessed individually and in combination with each other. ${ }^{17}$ It is widely recognized that copper chlorides and oxides are the strongest catalysts for $\mathrm{PCDD} / \mathrm{F}$ formation. ${ }^{18,19}$ Our previous study on the occurrence of $\mathrm{PCDD} / \mathrm{Fs}$ in industrial sources also indicated that fly ash from secondary copper process had higher PCDD/F concentrations than that from other secondary nonferrous smelting processes, primary nonferrous smelting processes, and steel making processes. ${ }^{16}$ Many studies have investigated the oxidation of chlorophenols and chlorobenzenes on the surface of silica-supported copper(II) oxide and iron(III) oxide to simulate the fly ash substrate and clarify the PCDD/F formation mechanism on such surfaces. ${ }^{9,20,21}$ On the basis of theoretical calculations, one study proposed that condensation of two chlorophenoxy radicals is a significant pathway for PCDD/Fs formation. ${ }^{22}$ Besides their contribution to PCDD/F formation, organic free radicals such as chlorophenoxy radicals are potential toxic and persistent in metal-containing particles, which suggested their environmental and health impacts of thermal processes especially the copper-smelting industries. ${ }^{23}$

The details of the PCDD/F formation mechanism on the molecular level are important for controlling PCDD/F formations in industrial thermal processes, and identification of the intermediates, including organic free radicals, during the thermochemical reactions of chlorophenol is required. In this study, 2,3,6-TCP was used as a precursor for formation of PCDD through thermochemical reactions under the catalysis of $\mathrm{Cu}(\mathrm{II}) \mathrm{O}$-containing silica. This method was used to simulate the particles-metallic oxide-chlorophenol system in fly ash. The occurrence of free radicals produced during the thermochemical reactions of 2,3,6-TCP were monitored by electron paramagnetic resonance (EPR) spectroscopy, which could provide direct evidence for understanding the mechanisms involved in PCDD formation. The intermediates detected by EPR were used to propose a PCDD formation mechanism using 2,3,6-TCP as the precursor, and this was verified by molecular orbital theory calculations. The results provide important knowledge for controlling $\mathrm{PCDD} / \mathrm{F}$ formation during industrial thermal processes.

\section{EXPERIMENTAL SECTION}

In Situ Detection of Free Radicals Involved in the Thermochemical Reactions of 2,3,6-TCP by EPR Spectroscopy. EPR spectroscopy is a powerful tool for detecting free radicals. In this study, the Dewar was inserted into the cavity of the EPR spectrometer for in situ detection of free radicals during thermochemical reactions of 2,3,6-TCP. The kinetic behavior of radical intermediates produced during the thermal reaction of chlorophenol were simulated and monitored. The Dewar was interfaced to a nitrogen container to allow steady detection and identification of radicals generated during the thermal process. Experiments were carried out by loading a 2,3,6-TCP standard (>98\% pure, Tokyo Chemical Industry Co., Tokyo, Japan) or a mixture of 2,3,6-TCP and 5\% $\mathrm{Cu}$ (II)O $/ \mathrm{SiO}_{2}$ (Sinopharm Chemical Reagent Co., Shanghai, China) into the EPR quartz tube (internal diameter (i.d.) = $4 \mathrm{~mm}$, length $=10 \mathrm{~mm}$ ) under a constant nitrogen flow at a temperature between 298 and $523 \mathrm{~K}$. The silica particles were heated in the air at $723 \mathrm{~K}$ for $4 \mathrm{~h}$ to remove potential organic contaminants on the surface. The quartz tube was located in an electrically heated Dewar under atmospheric pressure for heating. After heating, the solid samples were cooled to $298 \mathrm{~K}$ and stored in the dark for $48 \mathrm{~h}$. Then, the samples were analyzed again by EPR spectroscopy to assess the influence of particulate matter $\left(\mathrm{Cu}(\mathrm{II}) \mathrm{O} / \mathrm{SiO}_{2}\right)$ on radical lifetime.

All EPR spectra were recorded on a Bruker EMX-plus X-band EPR spectrometer (Bruker Instruments, Billerica, MA). The instrument and operating parameters were as follows: center field, $3520 \mathrm{G}$; microwave frequency, $9.36 \mathrm{GHz}$; microwave power, $0.63 \mathrm{~mW}$; modulation frequency, $100 \mathrm{kHz}$; modulation amplitude, $1.0 \mathrm{G}$; sweep width, $200 \mathrm{G}$; receiver gain, $30 \mathrm{~dB}$; and time constant, $0.01 \mathrm{~ms}$. Radical quantification was conducted using Bruker's Xenon program according to the quantitative theory of spin calculation (see the Supporting Information, SI).

Thermochemical Experiments for PCDD/F Formation from 2,3,6-TCP in a Tube Furnace for Capturing the Reaction Products. Thermochemical experiments were conducted to simulate the formation conditions of radicals and PCDD/Fs during industrial thermal process. Thermochemical experiments were performed using a tube furnace (GSL-1100X, Kejing Material Technology Co., Hefei, China) equipped with a quartz tube. A diagram of the apparatus is shown in Figure S1. Air was passed through the tube furnace at a constant flow rate of $50 \mathrm{~mL} \mathrm{~min}{ }^{-1}$. Silica is the main component of fly ash (5-50\%), and always acts as the support for transition metals in catalytic systems. ${ }^{8}$ As a surrogate for these particles, we used $\mathrm{Cu}$ (II)O ( $5 \%$ mass fraction) supported on silica. This was mixed with $0.1 \mathrm{~g}$ of 2,3,6-TCP standard to create a system to study interactions among specific, welldefined components of the fly ash. The reactant was placed in a porcelain boat, which was then placed in the middle of the furnace, and the furnace was heated to $250{ }^{\circ} \mathrm{C}$ for $15 \mathrm{~min}$ for the in situ reaction. The furnace temperature was increased at a rate of $10{ }^{\circ} \mathrm{C} \mathrm{min}^{-1}$. On the basis of the results of our previous study, more than $90 \%$ of the PCDD/Fs were in the gas phase at a reaction temperature of $523 \mathrm{~K}^{24}$ The gaseous products of the thermal process were captured by a toluene-filled absorption bottle held in an ice bath and connected to the end of the reaction tube. After heating, the reactor (a quartz tube) and all of the fittings were rinsed with toluene to recover any gas products deposited on the surfaces of the tube. The rinsing solution was then combined with the toluene from the absorption bottles. The solid residues and gas phase samples were extracted and cleaned according to a modification of the method described in our previous study. ${ }^{24}$

In addition, blank and contrast experiments were also carried out. The blank experiments involved running the tube furnace 
containing only $\mathrm{SiO}_{2}$, and again containing all reactants except the chlorophenols. The contrast experiment used a chlorophenol mixture without $\mathrm{Cu}(\mathrm{II}) \mathrm{O}$. The blank samples were used to determine the quantity of PCDD in the thermal reaction products generated from the particle surrogate samples, and this value was compared with that from the final samples. The contrast sample was used to evaluate the influence of metallic oxide on the formation of PCDDs. The yields of the products were calculated for comparison of the contrast samples with the experimental samples using the following equation: ${ }^{25,26}$

$$
\text { yield }=\left(\frac{[\text { product }] A}{[\text { reactant }]}\right) \times 100 \%
$$

where [product] is the concentration of PCDDs formed; [reactant] is the initial concentration of the reactants injected into the reactor tube; and $A$ is the molar stoichiometric factor, which was identified as two in this case because two reactant molecules $(2,3,6-\mathrm{TCP})$ can form one PCDD molecule.

Determination of the Reaction Products by Gas Chromatography Quadrupole Time-of-Flight Tandem Mass Spectrometry and High-Resolution Gas Chromatography with High-Resolution Mass Spectrometry. The gaseous products containing more than $90 \%$ of the total

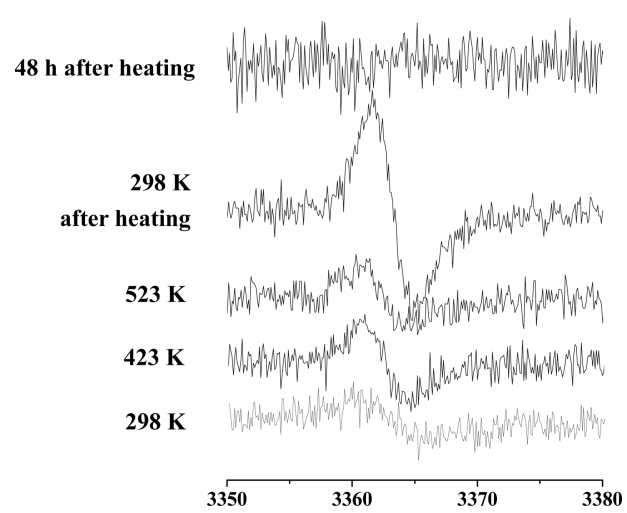

Figure 1. Electron spin resonance spectra of 2,3,6-trichlorophenol at (a) $298 \mathrm{~K}$, (b) $423 \mathrm{~K}$, (c) $523 \mathrm{~K}$, and (d) $298 \mathrm{~K}$ after heating and (e) $48 \mathrm{~h}$ after heating.
PCDD/Fs formed in the thermal process were cleaned using a multilayer silica gel column treated with $44 \%$ (mass fraction) sulfuric acid and 33\% (mass fraction) sodium hydroxide, concentrated to a volume of about $20 \mu \mathrm{L}$ using a rotary evaporator and a gentle stream of $\mathrm{N}_{2}$, and detected by gas chromatography combined with a quadrupole time-of-flight mass spectrometry (GC Q-TOF MS) (Agilent Technologies, Santa Clara, CA) and high-resolution gas chromatography/ high-resolution mass spectrometry (HRGC/HRMS). The GC Q-TOF MS measurements were carried out on an Agilent 7890 GC system coupled to a TOF mass spectrometer, operating in electron ionization mode. The GC separation was performed using a DB-5 MS fused silica capillary column $(30 \mathrm{~m} \times$ $0.25 \mathrm{~mm}$ i.d., $0.25 \mu \mathrm{m}$ film thickness; Agilent Technologies). The oven temperature was programmed as follows: $80{ }^{\circ} \mathrm{C}$ (hold $1 \mathrm{~min}$ ); increased at $20^{\circ} \mathrm{C} / \mathrm{min}$ to $120^{\circ} \mathrm{C}$; increased at $8{ }^{\circ} \mathrm{C} / \mathrm{min}$ to $200{ }^{\circ} \mathrm{C}$; increased at $20{ }^{\circ} \mathrm{C} / \mathrm{min}$ to $250{ }^{\circ} \mathrm{C}$; increased at $5{ }^{\circ} \mathrm{C} / \mathrm{min}$ to $310^{\circ} \mathrm{C}$ (hold $15 \mathrm{~min}$ ). Split injections of $1 \mu \mathrm{L}$ of sample were carried out. Helium was used as carrier gas at $1 \mathrm{~mL} / \mathrm{min}$. The interface and source temperatures were set to 300 and $250{ }^{\circ} \mathrm{C}$, respectively, and a solvent delay of 4 min was selected. In the TOF MS, five spectra were acquired per second in the mass range $m / z 50-650$. The qualifications were performed by NIST spectrum library matching. "Unknown compounds analysis" software in the Mass Hunter Workstation (Agilent Technologies) was also used for purification and classification of co-outflow peaks by deconvolution of the data sets, which could improve the unknown compounds matching accuracy with the spectral library and established an error limit of $2.3 \mathrm{ppm}$ for identification. Accurate identification and quantification of $\mathrm{PCDD} / \mathrm{Fs}$ in the gas phase were performed by HRGC/HRMS using a DB-5 ms capillary column $(60 \mathrm{~m} \times 0.25 \mathrm{~mm}$ i.d., $0.25 \mu \mathrm{m}$ film thickness; Agilent Technologies). The HRMS was operated in selected-ion monitoring mode at a resolution of $\geq 10000$. Details for the HRGC/ HRMS procedure were described in the SI. ${ }^{27}$

Simulation of EPR Spectrum and Density Functional Theory Calculation Used for Mechanism Verification. The Gaussian 09 suite of programs was used for density functional theory analysis of electronic structure calculations. ${ }^{28}$ MPWB1K is a hybrid functional that is based on the modified Perdew and Wang exchange functional and Becke's 1995

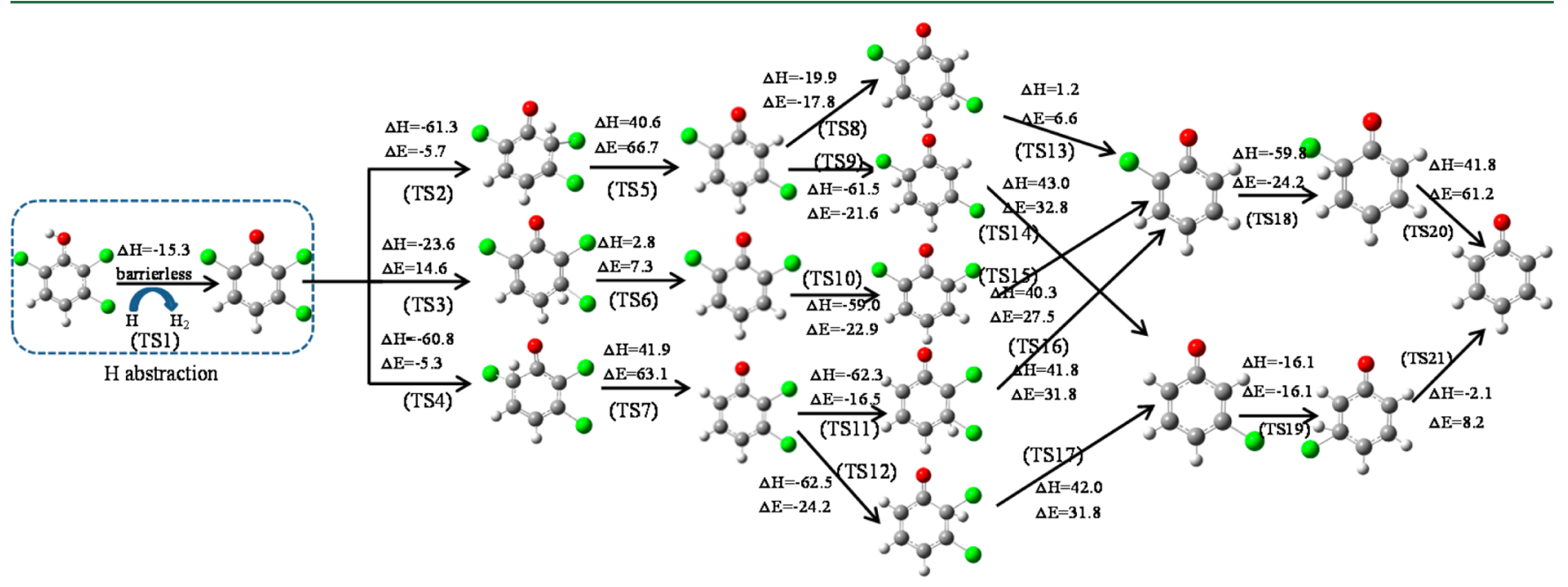

Figure 2. Schematic of the formation of 2,3,6-trichlorophenol radical and phenoxy radical from the reactions of 2,3,6-trichlorophenol with $\mathrm{H}$. Potential barriers $(\Delta E, \mathrm{kcal} / \mathrm{mol})$ and the heats of reaction $(\Delta H, \mathrm{kcal} / \mathrm{mol})$ are shown. 


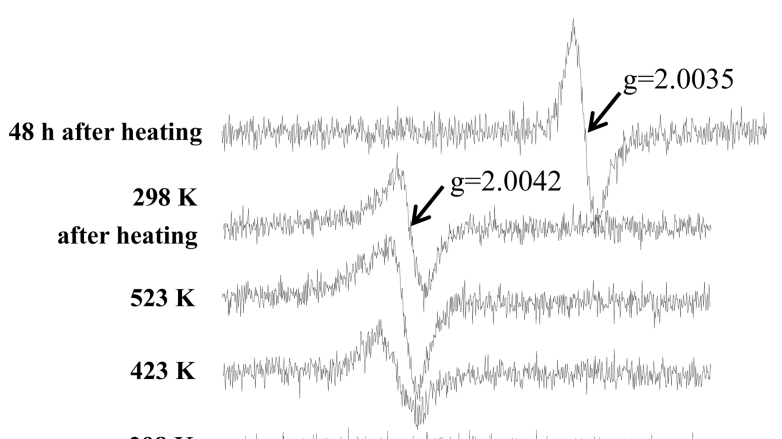

298 K

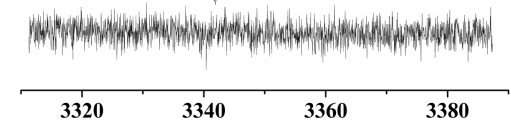

Figure 3. Electron spin resonance spectra of 2,3,6-trichlorophenol on the surface of silica-supported copper(II) oxide at (a) $298 \mathrm{~K}$, (b) $423 \mathrm{~K}$, (c) $523 \mathrm{~K}$, and (d) $298 \mathrm{~K}$ after heating and (e) $48 \mathrm{~h}$ after heating.

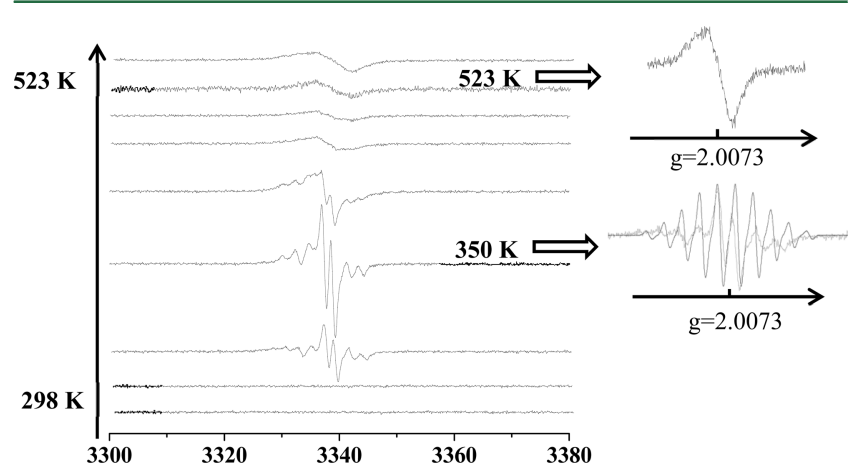

Figure 4. Dynamic changes in the electron spin resonance spectra of 2,3,6-trichlorophenol on the surface of silica-supported copper(II) oxide at 298 to $523 \mathrm{~K}$. The inset shows a comparison of the experimental (green) and the simulated (red) spectra.

correlation functional, and has been successfully used for the prediction of transition state geometries and thermochemical kinetics. ${ }^{14}$ Therefore, as a reasonable compromise between computation time and accuracy, the MPWB1K method and a standard $6-31+G(d, p)$ basis set were chosen for optimization of the geometries of the stationary points. ${ }^{29,30}$ Vibrational frequencies were calculated at the same level to check each geometry of the potential energy surface minimum.

\section{RESULTS AND DISCUSSION}

EPR Detection and Kinetic Calculations of Free Radicals Involved in the Thermochemical Reactions of 2,3,6-TCP. The most direct route for PCDD/F formation is the gas-phase reaction of chemical precursors. ${ }^{31}$ Therefore, 2,3,6-TCP was added on its own to the EPR quartz tube for in situ EPR spectroscopy as the temperature was increased from 298 to $523 \mathrm{~K}$. The results were used to monitor the generation of free radicals for comparison with the fly ash simulation system. A large quantity of free radicals was generated when the temperature increased (Figure 1), and the concentrations of free radicals were $1.906 \times 10^{17}$ spins $/ \mathrm{mm}^{3}$ and $1.559 \times 10^{17}$ spins $/ \mathrm{mm}^{3}$ at 423 and $523 \mathrm{~K}$, respectively. However, when the temperature dropped to $298 \mathrm{~K}$, the concentration of free radicals detected was twice that at $523 \mathrm{~K}$, which indicated that free radicals were generated in the same zone as $\mathrm{PCDD} / \mathrm{Fs}$ formed in, which is the cooling zone in the industrial thermal processes. When placed at room temperature $(298 \mathrm{~K})$ for $48 \mathrm{~h}$, an EPR signal was not detected.

It has shown that dimerization of chlorophenoxy radicals is the dominant pathway in the gas-phase formation of PCDD/Fs from chlorophenol precursors. ${ }^{32}$ Thus, the formation of chlorophenoxy radicals is the initial step in the formation of PCDD/ Fs. Besides, only chlorophenols with chlorine at the ortho position are considered capable of forming PCDDs, while parachlorophenol is responsible for PCDF formation. ${ }^{33}$ Therefore, hydrogen $(\mathrm{H})$ abstraction and dechlorination reaction process were calculated accurately to assess if formation of chlorophenoxy radicals and PCDD/Fs by these pathways is reasonable. The potential barriers $(\Delta E)$ and the heats of reaction $(\Delta H)$, which both include the ZPE correction, were calculated at the $\mathrm{MPWB} 1 K / 6-31+\mathrm{G}(\mathrm{d}, \mathrm{p})$ level. Calculated relative energies are given in Figure 2, and optimized geometries of $\mathrm{H}$ abstraction and dechlorinated transition states are denoted as TS1-TS21 in Figure S2. The $\mathrm{H}$ abstraction reaction can occur readily with unimolecular, bimolecular, or possibly other low-energy pathways like heterogeneous reactions. ${ }^{34,35}$ The unimolecular reaction occurs via the cleavage of the $\mathrm{O}-\mathrm{H}$ bond of chlorophenol. The bimolecular reactions proceed through the phenoxyl-H abstraction by active and abundant radicals like $\mathrm{H}, \mathrm{OH}$, and $\mathrm{Cl}$ in the combustion system. $\mathrm{H}$ abstraction occurs through a bimolecular reaction of the $\mathrm{H}$ radical, and is barrierless as the transition states with the ZPE correction are lower

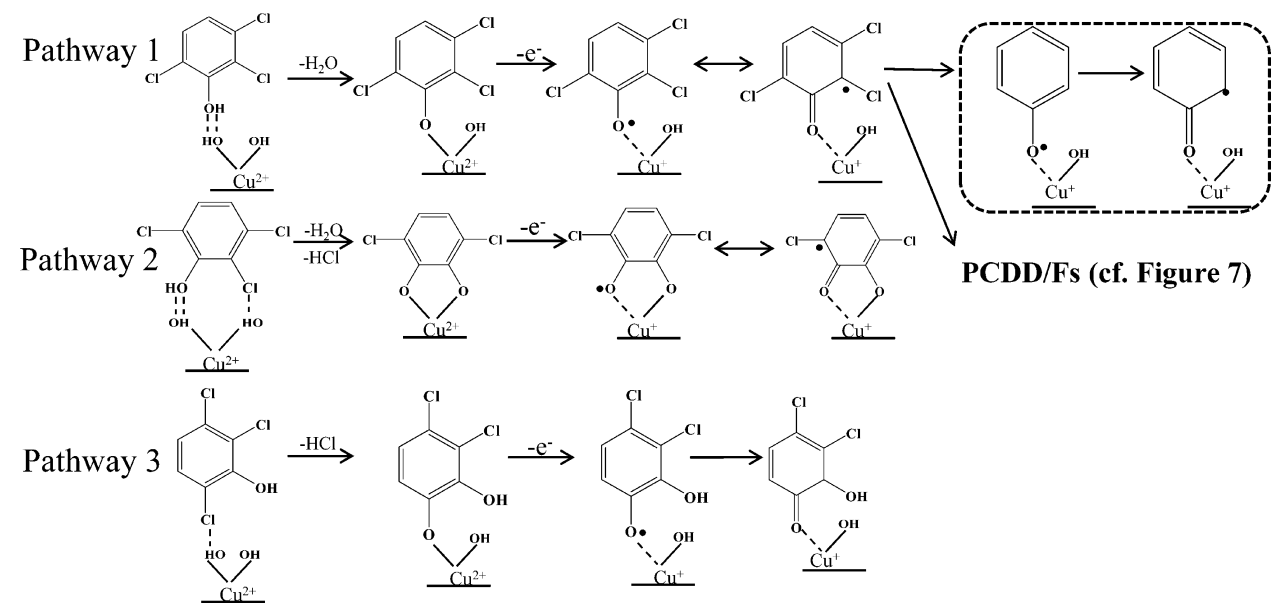

Figure 5. Three possible pathways for the formation of persistent free radicals of 2,3,6-trichlorophenol radical from 2,3,6-trichlorophenol on the surface of silica-supported copper(II) oxide. ${ }^{39}$ 
than the energies of reactants (Figure 2). In addition, the process is exothermic, and is an energetically feasible reaction for the formation of the TCP radical (TCPR) under pyrolysis or combustion conditions. Afterward, the EPR spectrum of the phenoxy radical suggests that hydrodechlorination of the chlorophenoxy radical can occur along with the increasing temperature. The dechlorination process has a relatively high heat of reaction and is endothermic, whereas the hydrogenation process is exothermic and can easily occur with no barrier to electron pairing (Figure 2). Therefore, it is easy to convert 2,3,6-TCP to 2,3,6-TRPR by $\mathrm{H}$ abstraction, and phenoxy radicals can be produced by hydrodechlorination only if there is sufficient thermal energy, which is consistent with our experimental results.

Persistent Free Radical Formation of 2,3,6-TCP on the Surface of Silica-Supported $\mathrm{Cu}$ (II) Oxide. $\mathrm{Cu}$ (II)Ocontaining silica was used as the thermal reaction substrate to simulate the fly ash system in this study. 2,3,6-TCP and 5\% $\mathrm{Cu}(\mathrm{II}) \mathrm{O} / \mathrm{SiO}_{2}$ were mixed thoroughly and placed in the EPR quartz tube to a height of $1 \mathrm{~cm}$ for the in situ detection. The mixture of $2,3,6-\mathrm{TCP}$ and $5 \% \mathrm{Cu}(\mathrm{II}) \mathrm{O} / \mathrm{SiO}_{2}$ did not generate free radicals at room temperature (Figure 3 ). When the temperature was increased to 423 or $523 \mathrm{~K}$, strong EPR signals were detected, and the free radical concentration was $6.158 \times 10^{17}$ spins $/ \mathrm{mm}^{3}$, which was about 38 times that of the same quantity of $2,3,6$-TCP at the same temperature. The large increase in the radical concentration indicated that the $\mathrm{Cu}(\mathrm{II}) \mathrm{O} / \mathrm{SiO}_{2}$ could trigger free radical formation. When the temperature dropped to $298 \mathrm{~K}$, the concentration of free radicals was $4.427 \times 10^{18}$ spins $/ \mathrm{mm}^{3}$, and seven times that at $523 \mathrm{~K}$. This result further implied that free radical and PCDD/F formation occur in the cooling zones of thermal processes. When placed at room temperature $(298 \mathrm{~K})$ for $48 \mathrm{~h}$, a strong EPR signal quantified as $2.187 \times 10^{18}$ spins $/ \mathrm{mm}^{3}$ was observed when the particulate matter and metallic oxide were present, which was different to the result obtained for the reaction of 2,3,6-TCP on its own. This result suggested that metal particles could extend the lifetime of free radicals produced by chlorophenol. Furthermore, the $g$ value of the free radicals shifted from 2.0042 at $423 \mathrm{~K}$ to 2.0035 at $298 \mathrm{~K}$ after heating, which suggests that type of free radical formed may change from oxygen-centered to a more stabilized carbon-centered phenoxy radical. $^{36}$

Figure 4 shows the dynamic changes in free radical intermediates formed in the particulate-metallic oxide-chlorophenol system when the temperature was increased from 298 to $523 \mathrm{~K}$. When at the temperature was around $350 \mathrm{~K}$, hyperfine splitting of ten peaks was detected. The results of simulation by the Isotropic Radicals program inferred that the hyperfine signals were generated by interaction of three chlorine nuclear spins and one electron spin of the TCPR. In general, a temperature increase will trigger $\mathrm{H}$ abstraction of TCP to form TCPR at around $350 \mathrm{~K}$, and further increases in the temperature will lead to dechlorination of TCPR to form phenoxy radicals. This indicated that the nonchlorine substituted phenoxyl-radical was much more stable than that of chlorine substituted phenoxy-radicals during the thermal processes, which was in agreement with that reported by Vejerano et al. ${ }^{37}$ As expected, the phenoxy radicals formed can persist and are stabilized by chemisorption to the metal oxide, with a single electron transfer to the metal cation center. ${ }^{17,38}$

Dela Cruz et al. proposed three possible pathways for environmentally persistent free radical (EPFR) formation from
Table 1. Compounds Tentatively Identified in the Gas Phase from the Tube Furnace Reaction, and the Main Parameters That Support Their Identification

\begin{tabular}{|c|c|c|c|c|c|}
\hline Name & Rention time & $\begin{array}{l}\text { GC-QTOF } \\
\text { Ion }(\mathrm{m} / \mathrm{z})\end{array}$ & Formula & $\begin{array}{l}\text { Error } \\
(\mathrm{ppm})\end{array}$ & Proposed structure \\
\hline \multirow{4}{*}{ TeCDDs } & 17.56 & \multirow{4}{*}{319.896} & \multirow{4}{*}{$\mathrm{C}_{12} \mathrm{H}_{4} \mathrm{Cl}_{4} \mathrm{O}_{2}$} & -0.5 & \\
\hline & 17.88 & & & -0.7 & \\
\hline & 18.17 & & & -0.7 & \\
\hline & 18.31 & & & -0.2 & \\
\hline \multirow{2}{*}{$\begin{array}{c}\text { Polychlorinat } \\
\text { ed diphenyl } \\
\text { ether }\end{array}$} & 18.02 & \multirow{2}{*}{303.9011} & \multirow{2}{*}{$\mathrm{C}_{12} \mathrm{H}_{4} \mathrm{Cl}_{6} \mathrm{O}$} & \multirow{2}{*}{--} & \\
\hline & 18.91 & & & & \\
\hline \multirow{2}{*}{ PeCDF } & 18.86 & \multirow{2}{*}{337.8622} & \multirow{2}{*}{$\mathrm{C}_{12} \mathrm{H}_{3} \mathrm{Cl}_{5} \mathrm{O}$} & -1.4 & \\
\hline & 19.55 & & & 0 & \\
\hline \multirow{3}{*}{ PeCDDs } & 19.02 & \multirow{3}{*}{353.8571} & \multirow{3}{*}{$\mathrm{C}_{12} \mathrm{H}_{3} \mathrm{Cl}_{5} \mathrm{O}_{2}$} & -1.1 & \\
\hline & 19.4 & & & -0.9 & \\
\hline & 19.75 & & & -0.7 & \\
\hline \multirow{2}{*}{$\begin{array}{l}\text { Polychlorinat } \\
\text { ed diphenyl } \\
\text { ether }\end{array}$} & 19.89 & \multirow{2}{*}{407.7998} & $\mathrm{C}_{12} \mathrm{H}_{3} \mathrm{Cl}_{7} \mathrm{O}$ & \multirow{2}{*}{--} & \\
\hline & 20.31 & & $\mathrm{C}_{12} \mathrm{H}_{3} \mathrm{Cl}_{7} \mathrm{O}$ & & \\
\hline \multirow{6}{*}{ HxCDDs } & 20.63 & \multirow{6}{*}{387.818} & \multirow{6}{*}{$\mathrm{C}_{12} \mathrm{H}_{2} \mathrm{Cl}_{6} \mathrm{O}_{2}$} & -0.4 & \\
\hline & 21.07 & & & -0.4 & \\
\hline & 21.13 & & & -0.4 & \\
\hline & 21.49 & & & -0.5 & \\
\hline & 21.59 & & & -0.5 & \\
\hline & 21.65 & & & -0.6 & \\
\hline \multirow{2}{*}{ HxCDFs } & 20.44 & \multirow{2}{*}{371.8232} & \multirow{2}{*}{$\mathrm{C}_{12} \mathrm{H}_{2} \mathrm{Cl}_{6} \mathrm{O}$} & 0 & \\
\hline & 20.92 & & & 0 & \\
\hline \multirow[b]{2}{*}{ HpCDDs } & 22.94 & \multirow[b]{2}{*}{421.7791} & \multirow[b]{2}{*}{$\mathrm{C}_{12} \mathrm{HCl}_{7} \mathrm{O}_{2}$} & -2.3 & \\
\hline & 23.45 & & & 0 & \\
\hline $\mathrm{HpCDF}$ & 22.73 & 405.7842 & $\mathrm{C}_{12} \mathrm{HCl}_{7} \mathrm{O}$ & 0 & \\
\hline OCDD & 25.45 & 455.7401 & $\mathrm{C}_{12} \mathrm{Cl}_{8} \mathrm{O}_{2}$ & -0.7 & \\
\hline $\begin{array}{c}\text { Polychlorinat } \\
\text { ed diphenyl } \\
\text { ether }\end{array}$ & 21.26 & 441.7614 & $\mathrm{C}_{12} \mathrm{H}_{2} \mathrm{Cl}_{8} \mathrm{O}$ & -- & \\
\hline $\begin{array}{c}\text { Tetrachloro-3 } \\
\text {-(dichloro-ph } \\
\text { enoxy)-diben } \\
\text { zo dioxin }\end{array}$ & 27.58 & 479.8456 & $\mathrm{C}_{18} \mathrm{H}_{6} \mathrm{Cl}_{6} \mathrm{O}_{3}$ & -- & \\
\hline $\begin{array}{c}\text { Pentachloro- } \\
\text { 3-(dichloro-p } \\
\text { henoxy)-dibe } \\
\text { nzo dioxin }\end{array}$ & 32.64 & 513.8058 & $\mathrm{C}_{18} \mathrm{H}_{5} \mathrm{Cl}_{7} \mathrm{O}_{3}$ & -- & \\
\hline
\end{tabular}

pentachlorophenol on the surface of $\mathrm{Fe}$ (III) oxide, which can also be adapted to the formation of the EPFRs of TCP on the surface of $\mathrm{Cu}$ (II) oxide (Figure 5). ${ }^{39}$ When chlorophenol is first absorbed on the $\mathrm{Cu}$ (II) oxide surface by physical absorption, loss of $\mathrm{H}_{2} \mathrm{O}$ occurs to form phenolate with simultaneous or rapid sequential electron transfer from the phenolate to $\mathrm{Cu}(\mathrm{II})$, which produces $\mathrm{Cu}(\mathrm{I})$ and the TCP EPFR. Oxygencentered and carbon-centered radicals can transform from one to the other. The second pathway is chemisorption through 


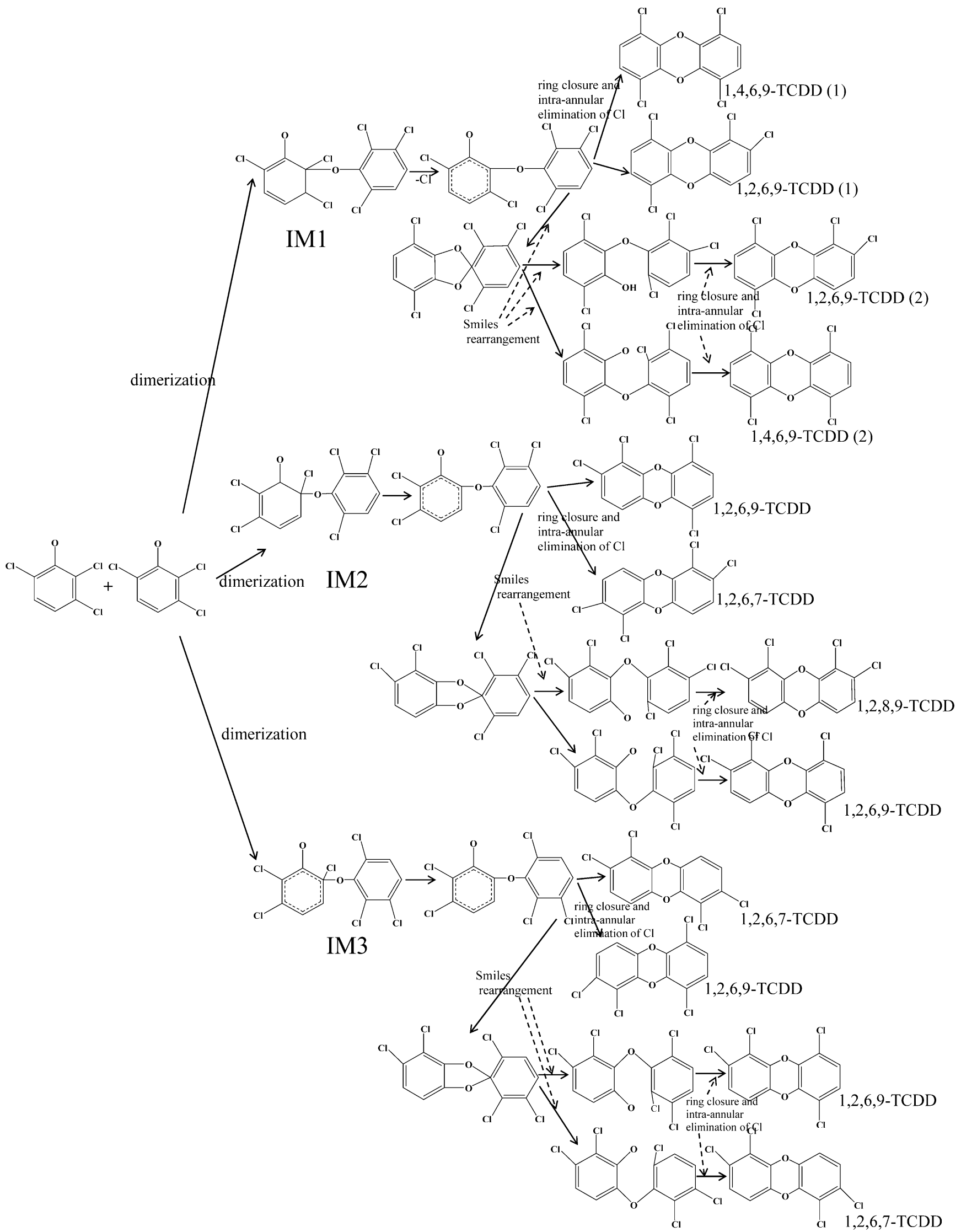

Figure 6. Proposed formation routes of tetrachlorodibenzo-p-dioxins (TeCDDs) involving the following five elementary processes: dimerization of 2,3,6- trichlorophenol radicals, ortho-chloride abstraction, Smiles rearrangement, ring closure, and intra-annular elimination of chloride. 
loss of $\mathrm{HCl}$ or both $\mathrm{HCl}$ and $\mathrm{H}_{2} \mathrm{O}$, and formation of a bichlorosemiquinone radical. Only the first and second pathways were observed in soils contaminated with chlorophenols under cool-zone conditions at temperatures between 150 and $600{ }^{\circ} \mathrm{C}$, even though the possibility of the third pathway cannot be ruled out in soil at ambient temperatures with reaction times of years. ${ }^{39}$ However, using the in situ reaction, we successfully monitored the hyperfine splitting signals of TCPR, which is the product of the first pathway. The result suggested that this pathway was the dominant formation mechanism of EPFRs during industrial thermal reactions at temperatures between 298 and $423 \mathrm{~K}$. In this temperature range, persistent phenoxy radicals could be formed along with PCDD/Fs in heterogeneous synthesis.

PCDD Formation of TCPR during Thermochemical Reactions in a Tube Furnace. The tube furnace reactions for simulation of industrial thermal process were first analyzed by GC Q-TOF MS as described in the Experimental Section. Figure S3 shows the total ion chromatograms obtained by analysis of the gaseous products in positive ionization modes. Peaks for 2,3,6-TCP and other chlorophenols eluted before 17 min. The principle products, PCDDs, PCDFs, polybrominated diphenyl ether, and polychloro-3-(polychlorophenoxy)dibenzo dioxin, were eluted after $17 \mathrm{~min}$. In total, $29 \mathrm{com}$ pounds were tentatively identified (Table 1) in the gas phase using TOF MS data in high resolution mode with an error below $2.3 \mathrm{ppm}$. Four tetrachlorodibenzo- $p$-dioxins (TeCDDs) (Figure S3) were the main products and gave the highest responses, which were approximately $10^{2}$ times than those of PeCDDs and HxCDDs, $10^{3}$ times those of HpCDDs, and $10^{4}$ times those of OCDD. The responses of PCDFs, polychlorinated diphenyl ether, and polychloro-3-(polychlorophenoxy)dibenzo dioxin were even lower. Formation of PCDD/Fs by the thermochemical reactions of 2-chlorophenol were previously reported. ${ }^{12}$ Mono- and dichlorinated congeners were expected to be the dominant PCDD/Fs. Actually, several products including 1-monochlorodibenzo- $p$-dioxin (1-MCDD), dibenzofuran (DF), chloronaphthalene were detected by GC/ MS when using 2-chlorophenol as precursor. ${ }^{12}$ In this study, four tetrachlorodibenzo- $p$-dioxins (TeCDDs) isomers were the dominant products formed by thermochemical reactions of 2,3,6-TCP. Although penta- to octa- chlorinated dioxin congeners were also detected by GC-TOF MS, their contents were far lower than that of TeCDD isomers.

It is widely recognized that PCDDs are formed via the $o$-phenoxy-phenol intermediate through oxygen-carbon coupling of TCPRs. ${ }^{13}$ Because of the asymmetric chlorine substitution, three $o$-phenoxy-phenol intermediates (IM1-IM3 in Figure 6) can be formed by TCPR coupling. We propose the formation of TeCDDs in gas phase radical-radical reactions (Figure 6) involves five elementary processes as follows: dimerization of TCPRs, ortho-chloride abstraction, Smiles rearrangement, ring closure, and intra-annular elimination of $\mathrm{Cl}$. These five elementary reactions lead to 1,2,6,9-TeCDD, 1,2,6,7-TeCDD, 1,4,6,9TeCDD, and 1,2,8,9-TeCDD as the main products from TCPR.

To identify and quantify the products of the tube furnace reaction, and to verify our proposed PCDD formation mechanism, isotope dilution HRGC/HRMS was used for further determination of the experimental samples and contrast samples in the tube furnace simulation experiment. Four TeCDDs (Figure S4) were identified by comparing the retention times with those of corresponding native standard compounds. The main products for the chromatographic peaks at 23.20, 24.90, 26.43, and $27.20 \mathrm{~min}$ were identified as 1,4,6,9-TeCDD, 1,2,6,9-TeCDD, 1,2,6,7TeCDD, and 1,2,8,9-TeCDD, respectively, which were the same as our expected products in gas phase reactions. The yields of $1,2,6,9-\mathrm{TeCDD}$ (5.7\%, percentage in the bracket indicated the yields) and 1,2,6,7-TeCDD (3.3\%) were higher than those of 1,4,6,9-TeCDD (0.3\%) and 1,2,8,9-TeCDD $(2.4 \%)$ in the experimental samples, which is in accordance with the speculation in Figure 6 that more pathways lead to formation of 1,2,6,9-TeCDD and 1,2,6,7-TeCDD than 1,4,6,9TeCDD and 1,2,8,9-TeCDD. The consistency between the experimental observations and our speculations for PCDD formation indicates the proposed mechanism is reasonable and valid. In addition, blank samples containing all other reactants except the chlorophenols were used to confirm that there was no obvious contamination from the $\mathrm{Cu}(\mathrm{II}) \mathrm{O} / \mathrm{SiO}_{2}$ reaction substrate, whose product yield was less than $0.0017 \%$ of that obtained from the experimental samples. The contrast sample containing the chlorophenol mixture without $\mathrm{Cu}(\mathrm{II}) \mathrm{O}$ was also used to investigate the catalytic activity of metallic oxide for PCDD formation in the thermal process. The yields of 1,4,6,9TeCDD, 1,2,6,9-TeCDD, 1,2,6,7-TeCDD, and 1,2,8,9-TeCDD for the contrast sample without the catalysis of $\mathrm{Cu}(\mathrm{II}) \mathrm{O}$ were $0.005 \%, 0.014 \%, 0.010 \%$, and $0.006 \%$, respectively. These results were all less than the $1.5 \%$ of those achieved for the experimental samples containing $5 \% \mathrm{Cu}(\mathrm{II}) \mathrm{O} / \mathrm{SiO}_{2}$. Furthermore, the gas phase reactions in Figure 6 only occurred at temperatures above $873 \mathrm{~K}$, and the PCDD formation results were the same as those in our simulation at $523 \mathrm{~K}$, which indicates that this is a surfacemediated process. ${ }^{40}$ This result implied that metallic oxides such as $\mathrm{Cu}(\mathrm{II}) \mathrm{O}$ are important for both stabilization of free radicals through chemisorption and electron transfer and catalysis of PCDD formation from chlorophenol.

\section{ASSOCIATED CONTENT}

\section{Supporting Information}

The Supporting Information is available free of charge on the ACS Publications website at DOI: 10.1021/acs.est.7b00828.

Details of HRGC/HRMS and radical quantification method, Figures S1-S4 (PDF)

\section{AUTHOR INFORMATION}

\section{Corresponding Authors}

*Tel: 8610 62849356; fax: 8610 62849355; e-mail: grliu@ rcees.ac.cn (G.L.).

*Tel: 8610 62849172; e-mail: zhengmh@rcees.ac.cn (M.Z.).

ORCID 8

Minghui Zheng: 0000-0002-8462-6734

Rong Jin: 0000-0001-9677-6177

Notes

The authors declare no competing financial interest.

\section{ACKNOWLEDGMENTS}

This work was supported by the Chinese National 973 Program (Grant No. 2015CB453100), the National Natural Science Foundation of China (Grant No. 91543108), the Strategic Priority Research Program of the Chinese Academy of Sciences (Grant No. XDB14020102), and the Youth Innovation Promotion Association of the Chinese Academy of Sciences (Grant No. 2016038). We appreciate Dr. Jiajia Wu from Agilent Technologies for her assistance on the GC-TOF MS analysis. 


\section{REFERENCES}

(1) Liu, G. R.; Jiang, X. X.; Wang, M.; Dong, S. J.; Zheng, M. H. Comparison of PCDD/F levels and profiles in fly ash samples from multiple industrial thermal sources. Chemosphere 2015, 133, 68-74.

(2) Stanmore, B. R. Modeling the formation of PCDD/F in solid waste incinerators. Chemosphere 2002, 47, 565-573.

(3) Khachatryan, L.; Burcat, A.; Dellinger, B. An elementary reactionkinetic model for the gas-phase formation of $1,3,6,8$ - and 1,3,7,9tetrachlorinated dibenzo-p-dioxins from 2,4,6-trichlorophenol. Combust. Flame 2003, 132, 406-421.

(4) Lavric, E.; Konnov, A.; Ruyck, J. Modeling the formation of precursors of dioxins during combustion of woody fuel volatiles. Fuel 2005, 84, 323-334.

(5) Blumenstock, M.; Zimmermann, R.; Schramm, K. W.; Kaune, A.; Nikolai, U.; Lenoir, D.; Kettrup, A. Estimation of the dioxin emission (PCDD/FI-TEQ) from the concentration of low chlorinated aromatic compounds in the flue and stack gas of a hazardous waste incinerator. J. Anal. Appl. Pyrolysis 1999, 49, 179-190.

(6) Fernandez-Castro, P.; San Roman, M. F.; Ortiz, I. Theoretical and experimental formation of low chlorinated dibenzo-p-dioxins and dibenzofurans in the Fenton oxidation of chlorophenol solutions. Chemosphere 2016, 161, 136-144.

(7) Ryu, J. Y.; Mulholland, J. A.; Kim, D. H.; Takeuchi, M. Homologue and isomer patterns of polychlorinated dibenzo-p-dioxins and dibenzofurans from phenol precursors: comparison with municipal waste incinerator data. Environ. Sci. Technol. 2005, 39, 4398-4406.

(8) Mosallanejad, S.; Dlugogorski, B. Z.; Kennedy, E. M.; Stockenhuber, M.; Lomnicki, S. M.; Assaf, N. W.; Altarawneh, M. Formation of $\mathrm{PCDD} / \mathrm{Fs}$ in Oxidation of 2-Chlorophenol on Neat Silica Surface. Environ. Sci. Technol. 2016, 50, 1412-1418.

(9) Nganai, S.; Dellinger, B.; Lomnicki, S. PCDD/PCDF ratio in the precursor formation model over $\mathrm{CuO}$ surface. Environ. Sci. Technol. 2014, 48, 13864-13870.

(10) Munoz, M.; Gomez-Rico, M. F.; Font, R. PCDD/F formation from chlorophenols by lignin and manganese peroxidases. Chemosphere 2014, 110, 129-135.

(11) Nganai, S.; Lomnicki, S. M.; Dellinger, B. Formation of PCDD/ Fs from the copper oxide-mediated pyrolysis and oxidation of 1,2dichlorobenzene. Environ. Sci. Technol. 2011, 45, 1034-1040.

(12) Evans, C. S.; Dellinger, B. Mechanisms of dioxin formation from the high-temperature pyrolysis of 2-chlorophenol. Environ. Sci. Technol. 2003, 37, 1325-1330.

(13) Zhang, Q.; Li, S.; Qu, X.; Shi, X.; Wang, W. A quantum mechanical study on the formation of PCDD/Fs from 2-chlorophenol as precursor. Environ. Sci. Technol. 2008, 42, 7301-7308.

(14) Zhang, Q.; Yu, W.; Zhang, R.; Zhou, Q.; Gao, R.; Wang, W. Quantum chemical and kinetic study on dioxin formation from the 2,4,6-TCP and 2,4-DCP precursors. Environ. Sci. Technol. 2010, 44, 3395-3403.

(15) Altwicker, E. R.; Konduri, R. K. N. V.; Lin, C.; Milligan, M. S. Rapid Formation of Polychlorinated Dioxins Furans in the Post Combustion Region during Heterogeneous Combustion. Chemosphere 1992, 25, 1935-1944.

(16) Jiang, X. X.; Liu, G. R.; Wang, M.; Zheng, M. H. Formation of polychlorinated biphenyls on secondary copper production fly ash: mechanistic aspects and correlation to other persistent organic pollutants. Sci. Rep. 2015, 5, 13903.

(17) Nwosu, U. G.; Roy, A.; dela Cruz, A. L.; Dellinger, B.; Cook, R. Formation of environmentally persistent free radical (EPFR) in iron(III) cation-exchanged smectite clay. Environmental Science: Processes \& impacts 2016, 18, 42-50.

(18) Chang, S. H.; Yeh, J. W.; Chein, H. M.; Hsu, L. Y.; Chi, K. H.; Chang, M. B. PCDD/F adsorption and destruction in the flue gas streams of MWI and MSP via $\mathrm{Cu}$ and $\mathrm{Fe}$ catalysts supported on carbon. Environ. Sci. Technol. 2008, 42, 5727-5733.

(19) Chin, Y. T.; Lin, C.; Chang-Chien, G. P.; Wang, Y. M. PCDD/F Formation Catalyzed by the Metal Chlorides and Chlorinated
Aromatic Compounds in Fly Ash. Aerosol Air Qual. Res. 2012, 12, 228-236.

(20) Caserini, S.; Monguzzi, A. M. PCDD/Fs emissions inventory in the Lombardy Region: results and uncertainties. Chemosphere 2002, $48,779-786$

(21) Lomnicki, S.; Dellinger, B. A detailed mechanism of the surfacemediated formation of PCDD/F from the oxidation of 2-chlorophenol on a $\mathrm{CuO} /$ silica surface. J. Phys. Chem. A 2003, 107, 4387-4395.

(22) Louw, R.; Ahonkhai, S. I. Radical/radical vs radical/molecule reactions in the formation of $\mathrm{PCDD} / \mathrm{Fs}$ from (chloro)phenols in incinerators. Chemosphere 2002, 46, 1273-1278.

(23) Vejerano, E.; Lomnicki, S.; Dellinger, B. Formation and Stabilization of Combustion-Generated Environmentally Persistent Free Radicals on an Fe(III)(2)O-3/Silica Surface. Environ. Sci. Technol. 2011, 45, 589-594.

(24) Wang, M.; Liu, G.; Jiang, X.; Xiao, K.; Zheng, M. Formation and potential mechanisms of polychlorinated dibenzo-p-dioxins and dibenzofurans on fly ash from a secondary copper smelting process. Environ. Sci. Pollut. Res. 2015, 22, 8747-8755.

(25) Nganai, S.; Lomnicki, S.; Dellinger, B. Ferric oxide mediated formation of $\mathrm{PCDD} / \mathrm{Fs}$ from 2-monochlorophenol. Environ. Sci. Technol. 2009, 43, 368-373.

(26) Nganai, S.; Lomnicki, S.; Dellinger, B. Formation of PCDD/Fs from oxidation of 2-monochlorophenol over an $\mathrm{Fe} 2 \mathrm{O} 3$ /silica surface. Chemosphere 2012, 88, 371-376.

(27) Yang, L.; Liu, G.; Zheng, M.; Jin, R.; Zhu, Q.; Zhao, Y.; Zhang, $\mathrm{X}$.; Xu, Y. Atmospheric occurrence and health risks of PCDD/Fs, polychlorinated biphenyls, and polychlorinated naphthalenes by air inhalation in metallurgical plants. Sci. Total Environ. 2017, 580, 11461154.

(28) Frisch, M. J.; Trucks, G. W.; Schlegel, H. B.; Scuseria, G. E.; Robb, M. A.; Cheeseman, J. R.; Scalmani, G.; Barone, V.; Mennucci, B.; Petersson, G. A.; Nakatsuji, H.; Caricato, M.; Li, X.; Hratchian, H. P.; Izmaylov, A. F.; Bloino, J.; Zheng, G.; Sonnenberg, J. L.; Hada, M.; Ehara, M.; Toyota, K.; Fukuda, R.; Hasegawa, J.; Ishida, M.; Nakajima, T.; Honda, Y.; Kitao, O.; Nakai, H.; Vreven, T.; Montgomery, J. A., Jr.; Peralta, J. E.; Ogliaro, F.; Bearpark, M.; Heyd, J. J.; Brothers, E.; Kudin, K. N.; Staroverov, V. N.; Kobayashi, R.; Normand, J.; Raghavachari, K.; Rendell, A.; Burant, J. C.; Iyengar, S. S.; Tomasi, J.; Cossi, M.; Rega, N.; Millam, J. M.; Klene, M.; Knox, J. E.; Cross, J. B.; Bakken, V.; Adamo, C.; Jaramillo, J.; Gomperts, R.; Stratmann, R. E.; Yazyev, O.; Austin, A. J.; Cammi, R.; Pomelli, C.; Ochterski, J. W.; Martin, R. L.; Morokuma, K.; Zakrzewski, V. G.; Voth, G. A.; Salvador, P.; Dannenberg, J. J.; Dapprich, S.; Daniels, A. D.; Farkas, O.; Foresman, J. B.; Ortiz, J. V.; Cioslowski, J.; Fox, D. J. Gaussian 09; Gaussian, Inc.: Wallingford, CT, 2009.

(29) Zhao, Y.; Truhlar, D. G. Hybrid meta density functional theory methods for thermochemistry, thermochemical kinetics, and noncovalent interactions: The MPW1B95 and MPWB1K models and comparative assessments for hydrogen bonding and van der Waals interactions. J. Phys. Chem. A 2004, 108, 6908-6918.

(30) Liu, G.; Zhan, J.; Zhao, Y.; Li, L.; Jiang, X.; Fu, J.; Li, C.; Zheng, M. Distributions, profiles and formation mechanisms of polychlorinated naphthalenes in cement kilns co-processing municipal waste incinerator fly ash. Chemosphere 2016, 155, 348-357.

(31) Khachatryan, L.; Asatryan, R.; Dellinger, B. Development of expanded and core kinetic models for the gas phase formation of dioxins from chlorinated phenols. Chemosphere 2003, 52, 695-708.

(32) Evans, C. S.; Dellinger, B. Mechanisms of dioxin formation from the high-temperature oxidation of 2-chlorophenol. Environ. Sci. Technol. 2005, 39, 122-127.

(33) Weber, R.; Hagenmaier, H. Mechanism of the formation of polychlorinated dibenzo-p-dioxins and dibenzofurans from chlorophenols in gas phase reactions. Chemosphere 1999, 38, 529-549.

(34) Evans, C. S.; Dellinger, B. Mechanisms of dioxin formation from the high-temperature pyrolysis of 2-bromophenol. Environ. Sci. Technol. 2003, 37, 5574-5580.

(35) Altarawneh, M.; Dlugogorski, B. Z.; Kennedy, E. M.; Mackie, J. C. Quantum chemical and kinetic study of formation of 
2-chlorophenoxy radical from 2-chlorophenol: unimolecular decomposition and bimolecular reactions with $\mathrm{H}, \mathrm{OH}, \mathrm{Cl}$, and $\mathrm{O}$. J. Phys. Chem. A 2008, 112, 3680-3692.

(36) Dellinger, B.; Lomnicki, S.; Khachatryan, L.; Maskos, Z.; Hall, R. W.; Adounkpe, J.; McFerrin, C.; Truong, H. Formation and stabilization of persistent free radicals. Proc. Combust. Inst. 2007, 31, 521-528.

(37) Vejerano, E.; Lomnicki, S. M.; Dellinger, B. Formation and Stabilization of Combustion-Generated, Environmentally Persistent Radicals on $\mathrm{Ni}(\mathrm{II}) \mathrm{O}$ Supported on a Silica Surface. Environ. Sci. Technol. 2012, 46, 9406-9411.

(38) Kiruri, L. W.; Khachatryan, L.; Dellinger, B.; Lomnicki, S. Effect of copper oxide concentration on the formation and persistency of environmentally persistent free radicals (EPFRs) in particulates. Environ. Sci. Technol. 2014, 48, 2212-2217.

(39) Dela Cruz, A. L. N.; Gehling, W.; Lomnicki, S.; Cook, R.; Dellinger, B. Detection of Environmentally Persistent Free Radicals at a Superfund Wood Treating Site. Environ. Sci. Technol. 2011, 45, 6356-6365.

(40) Chatterjee, D.; Deutschmann, O.; Warnatz, J. Detailed surface reaction mechanism in a three-way catalyst. Faraday Discuss. 2001, 119, 371-384. 